\title{
The impact of the implementation of the green bond policy on enterprises' innovation performance
}

\author{
Haoya Chen ${ }^{1,{ }^{*} \dagger}$, Yuqiao $\mathrm{Li}^{2,{ }^{*} \dagger}$, Dingwen Sun ${ }^{3,{ }^{*}+}$ \\ ${ }^{1}$ School of Social Science, University of Manchester, Manchester, UK \\ ${ }^{2}$ School of Economics and Management, Guangxi Normal University, Guilin, China \\ ${ }^{3}$ Department of Economics, Shanghai Jiao Tong University, Shanghai, China \\ *Corresponding author: sdw2326911491@sjtu.edu.cn, lyq@stu.gxnu.edu.cn, \\ haoya.chen@student.manchester.ac.uk
}

†These authors contributed equally.

\begin{abstract}
The institutional construction of green financial bonds in China began at the end of 2015 and developed rapidly in 2016 and 2017 . Based on the background of sustainable development, this article explores the implementation significance of the green bond policy from environmental protection, financial development, and technological innovation. Specifically, the incentive effects of the green bond policy on the technological innovation of enterprises with different levels of pollution are investigated in terms of the difference-in-differences model. According to the analysis, after the implementation of the green bond policy, there is a greater difference in the innovation capabilities between the medium- and high-pollution enterprises and the low-pollution enterprises. Solvency has a negative impact on innovation incentives, profitability and enterprise size have a positive impact on innovation incentives, while development capabilities and age have little effect. Finally, suggestions are put forward to improve the incentive mechanism of green bonds and establish the policy effect evaluation system, so as to promote the sustainable development of enterprises and the high-quality development of green bonds. These results shed light on the significance of green bond policy implementation and point out the direction of enterprise transformation and upgrading in the future.
\end{abstract}

Keywords: green bond; DID Model; innovation performance.

\section{Introduction}

The industrial sector is a major polluter [1], which is imperative to promote green technology, improve pollution control technology and strengthen research and development of clean technology. Green finance, as an important practical exploration of financial regulation and control in the field of environmental governance, can contribute on the financial resource allocation and environmental regulation. As one of the important green financial measures, green bonds are marketable securities issued by legal persons of financial institutions, which raised funds to support green industries, and repayment of principal and interest as agreed. The scale of China's green bond market has continued to be improved in issuers, insurance varieties, methods, standard in the issuers [2].

Since 2015, China has successively issued the Catalogue of Green Bond Support Projects and other documents, which directly stimulated the expansion of the green bond market. Green bond policy can make full use of financial risk management technology and promote green investment with the help of market mechanism, government control and social supervision. In order to win the corresponding development opportunities in the green bond policy, state-owned enterprises and investment companies in all provinces and cities have gradually applied for issuing green bonds since 2016 to invest more funds in green industries.

In fact, in the context of the "dual-carbon" target, green bonds, as an important exploration to seek coordinated development of environmental governance and economy, have become a very important part of the process of economic green transformation and upgrading. Inspired by the green bond policy, it has become a common practice for companies to develop a green economy. Theoretically speaking, the green bond policy will affect the company's internal capital investment and 
technological innovation decisions. When the external pressure generated by green bonds affects the survival and development of the company, it will stimulate the company's strong impulse for independent innovation, prompt the company to increase investment in research and development, and commit to the promotion and application of key environmental protection technologies. Therefore, an in-depth discussion on whether green bond policies will affect corporate innovation decisionmaking is needed to address. Besides, whether it can promote corporate technological adjustments, and then identify policy deviations in the implementation process and understand the underlying mechanism is of great significance for evaluating the effectiveness of incentives. This paper will conduct an empirical analysis based on the difference-in-differences model to investigate the incentive effect of green bond policies on the technological innovation of enterprises with different pollution levels, and provide a reference for further promoting green development.

\section{Research gap}

\subsection{Explanatory variables}

There are several articles analyzing green finance and environmental issues, the impact of polluters on the environment cannot be ignored, and for decades the ecological deficit has been growing, undermining the planets' ability to support life as we know it. For the incentive to polluting firms, $\mathrm{Hu}$, Wang, and Wang studied the innovative impact of green credit policies on highly polluting enterprises, during they examine the stimulating effects of green credit on polluting firms in China and the mechanisms through which these stimulating effects pass, they do not account for the role of other green financial policies on corporate environmental governance, e.g., the role of green bonds, which is examined in this paper [3]. There are also articles describing the price of green bonds in terms of the impact of environmental preferences on them. Zerbib uses a two-step regression procedure with the example of green bonds to conclude that the yield on green bonds is lower than that on conventional bonds, that there is a small negative premium. Besides, the impact of investors' environmental preferences on bond prices are smaller but does not represent a disincentive to support the expansion of the green bond market at this stage of the investor segment [4]. This article presents an analytical study of the price of green bonds as a tool to identify the impact of non-pecuniary motives, particularly environmentally beneficial preferences, on bond market prices. However, it again does not address the impact of green bonds on specific polluters. On the impact of green bonds on financing the low carbon transition, Heine suggests that the joint use of green bonds and carbon pricing could bring significant benefits to a country's low-carbon, climate-resilient economic transition, and that carbon pricing could improve the performance of green bonds. Therefore, it improves intergenerational equity, political viability, and helps to address multiple market failures [5]. This demonstrates the importance of green bonds to the transition to a low carbon economy, making the usage of green bonds to incentivize polluters to reduce their emissions even more significant. For green finance and the environment, this paper examines the responses of heavily polluting and moderately polluting enterprises to the implementation of green bond policies and finds that the patents granted to highly polluting and low polluting enterprises are not the same.

With specific reference to the response of some investor to green bonds, Sangiorgi and Schopohl conducted a questionnaire survey of forty-eight European asset managers to gain insight into investor's green bond investment activity. Based on the analysis, they found that most respondents were actively investing in the green bond market through a variety of channels, including direct investment, green bond funds and green mandates. The survey evidence suggests that issuers are raising additional the untapped potential for issuers to raise additional debt capital in the green bond market. To be specific, the "greenness" of green bonds is an important investment consideration, and that issuers need to ensure that their bonds meet the environmental benefits excepted by investors [6]. This illustrates the attitude of some institutional investors towards the purchase of green bonds, with the majority actively investing in green bonds, which could be strengthened as an important investment consideration if there was more specific and direct analysis of the incentive impact of 
green bonds on polluting companies and could lead to a stronger willingness to invest. The willingness to invest in green bonds can be explained by the value of equity returns, as some investors may look at the yield on investments in green bonds.

\subsection{Control variables}

Contemporary research on the green financial system certainly has much focus on green bonds. Fatica, Panzica and Rancan suggests that the issuance of green bonds is not always at a premium to regular bonds and has no impact on financial issuers. According to a series of tests, they find that the green bond label itself is not sufficient to raise funds at a lower cost. A possible explanation is that investors have difficulty putting real issuers that are truly committed to environmental projects from those that are simply "drifting" [7]. However, this article focuses on the price of green bonds themselves and dose not examine the incentive benefits of green bonds for polluters. The motivations of Chinese commercial banks to issue green bonds has also been discussed, with the regulatory arbitrage mechanism being an important incentive for commercial banks to issue green bonds. Therefore, green bonds could change the financial structure of a company by changing the financial cost of its operation and increasing the liquidity of its assets.

When it comes specifically to whether shareholders can profit from green bonds, Tang and Zhang stated that share prices of issuers rose significantly around the time of green bond issuance announcements [8]. The stock market reacts more strongly to first-time issuers than to multiple issuers, green bonds help to broaden the investor base as issuing green bonds attract more media exposure and is used by impact investors to meet their investment mandates. In addition, existing shareholders receive a net gain from green bond issuance. This suggests that green bonds are more likely to provide incentives for polluters to reduce their emissions, but this article does not analyze how green bonds provide incentives for polluters. Overall, the issuance of green bond policies improves corporate earnings by changing the returns on the stock market and the internal operations of the company. In the following data analysis, we will use the return on equity to make a specific analysis of this problem.

\section{Data and methodology}

\subsection{Data description}

We choose the total number of patents applied for, obtained and granted by the enterprise in the year as the dependent variable in this paper, as an indicator of an enterprise's innovation performance. The number of patents owned by an enterprise can represent an important indicator of R\&D capability, and $R \& D$ capability is the technical premise and foundation of technological innovation capability [9]. The selected sample is the data related to A-shares listed industrial companies for a total of ten years from 2010 to 2020 . All data is obtained from CSMAR, and the final data has been cleaned by excluding ST stocks. All data with a total patent count of 0 was excluded, followed by a $1 \%$ tailoring. Finally, the available sample consists of 203 A-share listed industrial companies with a total of 651 data for 10 years from 2010 to 2020. All variable descriptions and data definitions are provided in Table 1.

Of which, pollution is the $0-1$ variable of whether the enterprise/industry is moderately or highly polluting. It is used to identify the pollution attributes of enterprises, and when it is equal to 1 , it means a highly polluting enterprise and an intervention group, otherwise it is a control group. This index refers to the classification criteria in the book: "Environmental Protection and the International Competitiveness of Industries: A Theoretical and Empirical Analysis" [10]. Since the implementation of the green bond policy is scheduled for December 2015, post is a 0-1 variable of whether the time is after December 2015. If it is after December 2015, it is 1 , and is 0 vice versa. Since patent data are annual, in this paper, we consider that the post value is 0 for data from 2015 and earlier, and 1 for data from 2016 and later. 
Table 1. Descriptive Statistics

\begin{tabular}{|c|c|c|c|c|c|c|}
\hline Variable & Definition & Obs & Mean & $\begin{array}{c}\text { Std. } \\
\text { Dev. }\end{array}$ & Min & Max \\
\hline patentsfin & $\begin{array}{c}\text { The total number of patents applied for, obtained } \\
\text { and granted by the enterprise in the year }\end{array}$ & 651 & 82.066 & 132.241 & 2 & 802 \\
\hline pollution & $\begin{array}{c}0-1 \text { variable of whether the enterprise's industry is } \\
\text { moderately or highly polluting }\end{array}$ & 651 & .161 & .368 & 0 & 1 \\
\hline post & $0-1$ variables around December 2015 & 651 & .439 & .497 & 0 & 1 \\
\hline qr & Solvency: Quick Ratio & 651 & 2.85 & 4.093 & .5 & 31.535 \\
\hline roe & Profitability: Return on Equity & 651 & .075 & .081 & -.293 & .276 \\
\hline agr & Development capacity: Total Assets Growth Rate & 651 & 30.211 & 49.078 & -22.11 & 262.28 \\
\hline lna & $\begin{array}{c}\text { Scale of the enterprise: Logarithmic value of Total } \\
\text { Assets }\end{array}$ & 651 & 21.813 & .817 & 20.246 & 24.188 \\
\hline age & $\begin{array}{c}\text { Difference between the current year and the year of } \\
\text { establishment of the enterprise }\end{array}$ & 651 & 14.052 & 6.167 & 3 & 31 \\
\hline
\end{tabular}

The mean value of the explained variable, the total number of patents of enterprises in the current period, is 82.066, which indicates that the average number of patents of the overall enterprises is low and technological innovation capability is still at a low level. The difference of its maximum value reaches 800 , which indicates that the number of patents of different enterprises has drawn a big gap. The control variables show that the enterprises in the sample are generally large in size, but there are huge gaps in solvency and development capacity. Some of the enterprises have weak profitability and are in a loss-making situation. The age of the enterprises is between 3-31, which shows a large difference.

\subsection{Methods}

In this section, we discuss whether, or not, the launch of green bonds can stimulate technological innovation capability of enterprises, by means of the DID method.

$$
\text { patentsfin }_{i t}=\beta_{0}+\beta_{1} \text { polt }_{i t}+\beta_{2} \text { pollution }_{i}+\beta_{3} \text { post }_{t}+\beta_{4} X_{i t}+\mu_{i}+\varepsilon_{i t}
$$

We use low pollution level enterprises $\left(\right.$ pollution $\left._{\mathrm{i}}=0\right)$ as controlled group, other enterprises (pollution $_{\mathrm{i}}=1$ ) as treated group. Besides, post $_{\mathrm{t}}=0$ refers to pre-implementation period. After the green bonds policy was implemented, post $_{t}=1$. polt $t_{\text {it }}$ is the interaction term of pollution and post, i.e., polt $_{i t}=$ pollution $_{\mathrm{i}} \times$ post $_{\mathrm{t}}$, whose coefficient $\beta_{1}$ indicates the separate effect of pollution level. The conclusions of interest in this paper will also be shown by $\beta_{1}$. The estimated coefficients are shown in table 2. 
Table 2. Regression result

\begin{tabular}{|c|c|c|c|c|c|c|c|}
\hline & $(1)$ & $(2)$ & (3) & (4) & $(5)$ & (6) & (7) \\
\hline $\begin{array}{c}\text { VARIABL } \\
\text { ES }\end{array}$ & Patentsfin & Patentsfin & Patentsfin & Patentsfin & Patentsfin & Patentsfin & Patentsfin \\
\hline \multirow[t]{2}{*}{ polt } & -35.1864 & -41.5625 & -40.4186 & $-51.6422 * *$ & -40.0574 & $-48.9031 *$ & $-48.9031 * * *$ \\
\hline & $(-1.28)$ & $(-1.51)$ & $(-1.47)$ & $(-2.07)$ & $(-1.46)$ & $(-1.96)$ & $(-3.06)$ \\
\hline \multirow[t]{2}{*}{ pollution } & $\begin{array}{c}- \\
46.0658 * *\end{array}$ & $\begin{array}{c}- \\
41.4934 * *\end{array}$ & $\begin{array}{c}- \\
42.1305 * *\end{array}$ & $-39.3182 * *$ & $45.0117 * *$ & $-39.7385^{* *}$ & $-39.7385 * * *$ \\
\hline & $(-2.50)$ & $(-2.24)$ & $(-2.27)$ & $(-2.35)$ & $(-2.42)$ & $(-2.35)$ & $(-4.59)$ \\
\hline \multirow[t]{2}{*}{ time } & $\begin{array}{c}45.0677 * * \\
*\end{array}$ & $\begin{array}{c}53.9716^{* *} \\
*\end{array}$ & $\begin{array}{c}54.0542 * * \\
*\end{array}$ & 4.4492 & $\begin{array}{c}57.5994 * * \\
*\end{array}$ & 1.4589 & 1.4589 \\
\hline & $(3.99)$ & $(4.86)$ & $(4.81)$ & $(0.41)$ & $(4.83)$ & $(0.12)$ & $(0.12)$ \\
\hline \multirow[t]{2}{*}{$\mathrm{qr}$} & $\begin{array}{c}- \\
3.7311 * * *\end{array}$ & & & & & $-2.0820 *$ & $-2.0820 * * *$ \\
\hline & $(-2.98)$ & & & & & $(-1.80)$ & $(-2.89)$ \\
\hline \multirow[t]{2}{*}{ roe } & & $104.5026^{*}$ & & & & 40.7587 & 40.7587 \\
\hline & & $(1.68)$ & & & & $(0.69)$ & $(0.61)$ \\
\hline \multirow[t]{2}{*}{ agr } & & & 0.1010 & & & 0.0547 & 0.0547 \\
\hline & & & $(0.97)$ & & & $(0.54)$ & $(0.35)$ \\
\hline \multirow[t]{2}{*}{$\ln a$} & & & & $73.6727 * * *$ & & $71.9978 * * *$ & $71.9978 * * *$ \\
\hline & & & & $(12.03)$ & & $(11.53)$ & $(7.85)$ \\
\hline \multirow[t]{2}{*}{ age } & & & & & -1.0714 & 0.3248 & 0.3248 \\
\hline & & & & & $(-1.19)$ & $(0.39)$ & $(0.44)$ \\
\hline \multirow[t]{2}{*}{ Constant } & $\begin{array}{c}82.9240 * * \\
*\end{array}$ & $\begin{array}{c}60.2501 * * \\
*\end{array}$ & $\begin{array}{c}65.0418 * * \\
*\end{array}$ & $\begin{array}{c}- \\
1,516.7418 * \\
* *\end{array}$ & $\begin{array}{c}82.0301 * * \\
*\end{array}$ & $\begin{array}{c}- \\
1,482.3790 * \\
* *\end{array}$ & $\begin{array}{c}- \\
1,482.3790 * \\
* *\end{array}$ \\
\hline & $(9.58)$ & $(6.72)$ & $(7.78)$ & $(-11.50)$ & $(6.23)$ & $(-10.87)$ & $(-7.59)$ \\
\hline $\begin{array}{c}\text { Observation } \\
\mathrm{s}\end{array}$ & 651 & 651 & 651 & 651 & 651 & 651 & 651 \\
\hline R-squared & 0.073 & 0.065 & 0.062 & 0.233 & 0.063 & 0.238 & 0.238 \\
\hline
\end{tabular}

$\mathrm{t}$-statistics in parentheses $* * * \mathrm{p}<0.01, * * \mathrm{p}<0.05, * \mathrm{p}<0.1$

\section{Empirical results and analysis}

In Table 2, columns 1 to 5 are the DID regressions result with the addition of qr, roe, agr, lna, age as control variables, respectively. The sixth column is the DID regression result with all of the above control variables added. After the heteroskedasticity test, we find there is heteroskedasticity problem in the regression. Hence, the seventh column is the regression result on the basis of the sixth column using robust to control for heteroskedasticity.

Based on Table 2, we can find out that the estimated coefficients of interaction term (polt $\mathrm{it}_{\mathrm{i}}$ ) are all negative and the values are all less than -35, but in columns 1,2,3 and 5 the coefficients are not statistically significant. In column 7, after adding all control variables and controlling for heteroskedasticity, the value of the estimated coefficient is -48.9031 , and it is significant at the $1 \%$ level. The result indicates that after the introduction of green bonds, the total number of patents applied for, obtained and granted by moderately or highly polluting enterprises in the year is 48.903 fewer than the one by low pollution enterprises. This is roughly the same as the conclusion drawn by Cao when studying the green effect and impact mechanism of the green credit policy [11]. The main reason is that after the implementation of such green financial policies, companies will face more 
severe financing constraints, and at the same time, there will be breakthroughs in technology, and the number of green invention patents will naturally drop more.

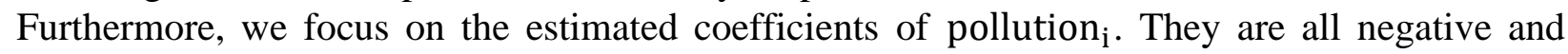
significant at the 5\% level. In the seventh column, the value of the estimated coefficient is -39.7385 . It shows that before the implementation of the green bonds policy, the total number of patents applied for, obtained and granted by moderately or highly polluting enterprises in the year is 39.7385 fewer than the one by low pollution enterprises. This result is in line with previous literature [12] that the negative impact on technological innovation of large-scale high-polluting enterprises is relatively greater.

Although the values and significances of estimated coefficients of time vary widely in different columns, they are all positive, indicating that the introduction of green bonds has a positive stimulus on the number of current patents for all enterprises. Then, we are concerned about the estimated coefficients of the control variables.

\subsection{Solvency}

When we only consider the solvency of the enterprises, the estimated coefficients of qr in column 1 is -3.7311 . In column 6 and 7, the value of the estimated coefficients changes to -2.0820 and it is significant at the $1 \%$ level. The result indicates that the solvency of the enterprises has negative effect on the number of current patents of the enterprises. As Tom illustrates, the green bond market needs to encourage its investors to buy green bonds by easing the insurance industry's solvency, as one survey shows that insurers have $\$ 900$ billion of investable assets within them, but they are hampered by solvency. Under rules regulating the insurance industry, investors are not allowed to buy noninvestment grade products - which typically include green bonds [13].

\subsection{Profitability}

In column 2, we only add roe as control variable. The estimated coefficient of roe is 104.5026 and it is significant at the $10 \%$ level. After adding all control variables and controlling for heteroskedasticity, in column 6 and 7, the value of the roe estimated coefficient is 40.7587, and is not statistically significant. Nevertheless, since all the estimated coefficients are positive, we can still make the conclusion that the profitability has positive effect on the number of current patents of the enterprises. Yang pointed out that patents will help companies produce new products or services, or improved products or services, and realize the growth of corporate operating efficiency; companies can also use patent authorization, transactions and other methods to increase corporate profits [14]. Successful intellectual property innovation activities will lead to an increase in the profitability of an enterprise, an increase in market share, and the quality of enterprise members. The enhancement of the overall capabilities of the enterprise will further enhance the intellectual property innovation capabilities of the enterprise and form a virtuous circle. In addition, Narin and Noma also give an example of a very large increase in sales and profits for SmithKline thanks to the anti-ulcer drug Tagamet, and many of SmithKline's highly cited patents are Tagamet patents [15].

\subsection{Development capacity}

In column 3, 6 and 7, the estimated coefficients of agr are all positive but close to 0 . Besides, none of them are statistically significant. Therefore, we conclude that development capacity has little effect on the number of current patents of the enterprises. Luo pointed out that due to the periodicity of patent application protection and the continuous iterative update of technology, patent advantages are not long-lasting [16]. In general, the number of invention patents has a significant positive correlation with the current profitability of enterprises. Based on patent analysis, companies can obtain valuable information about technology trends and the position of competitors, identify important technological developments, and manage their patent portfolios. Moreover, decisions regarding the direction of a company's patent portfolio will greatly benefit the company's future strategic planning [17]. 


\subsection{Scale of the enterprise}

In column 4, 6 and 7, the estimated coefficients of lna are all positive and the value of which are bigger than 70 . All of them are statistically significant at the $1 \%$ level. It shows that the scale of the enterprise has a large positive impact on its the number of current patents. It may because it's the larger companies that are concerned about the environment, and the smaller companies that are not. Small companies are only financing themselves through green bonds and not really concerned about the environment, so the money received from green bonds is not used to really enhance the innovation capacity of companies. Mi believes that the market control power of a company can be judged by the market share of a company [18]. For companies with strong market control, the market share brought by technological progress is higher, i.e., they can Internalization of externalities, forming selftechnological progress and upgrading of technological structure. Thraneen and Vulturius also suggest that most issuers do not link green bonds to climate targets and do not incorporate both in a comprehensive way to manage their transition to carbon neutrality [19].

\subsection{Age}

In column 5, 6 and 7, the estimated coefficients of age are all around zero and not statistically significant. Thus, we draw the conclusion that age has little effect on the number of current patents of the enterprises. When researching the relationship between corporate age and innovation, NISTEP of Japan pointed out: The relationship between corporate age and innovation is complex, and it is not clear that young companies have advantages over mature companies in terms of innovation. In terms of innovation awareness, young companies are higher than mature companies. As for innovation capabilities, compared to the age of the company, the size of the company has a greater impact; in terms of learning new knowledge and new technologies, mature companies can effectively absorb advanced knowledge and technology, which is better than younger ones. However, the problem of rigid organization of mature enterprises is serious, and there is a risk of passive treatment of investment in innovative $R \& D$ projects. As Laforet illustrates, when it comes to innovation, the relative advantage of large companies lies primarily in resources [20]. These resources include economies of scale, financial resources, the possibility of spreading risk and a greater capacity to specialize in people and equipment. Smaller companies are usually explained by behavioral characteristics. Younger and smaller firms confer a degree of flexibility and agility. This means that large companies and small companies each have their own advantages.

\section{Conclusion}

In summary, based on the relevant data of listed industrial companies, this paper uses the DID method to test the incentive impact of green bond policies on the green innovation activities of enterprises with different pollution levels. According to the results, compared with low-polluting enterprises, the implementation of the green bond policy has inhibited the green innovation activities of medium- and high-polluting enterprises as a whole (-48.9031). Notably to mention, before the policy was implemented, medium- and high-polluting enterprises already had fewer 39.7385 patents than low-polluting enterprises. In terms of control variables, solvency of the enterprises has negative effect, profitability and scale have positive effect, and development capacity and age have little effect on the number of current patents of the enterprises.

Based on the above research conclusions, this article proposes the following policy implications. First of all, we need to improve the green bond incentive mechanism to stimulate the internal driving force of enterprises' innovation and transformation. According to the research in this article, although the green bond policy has promoted the trend of green development in the industry, it has affected the investment and innovation decision-making within the enterprise, and has caused the survival of the fittest among enterprises and the reallocation of market share. Nevertheless, at the initial stage of the implementation of the green bond policy, due to the lack of detailed implementation rules and supporting policies, high-polluting companies responded passively instead of actively adopting 
technological innovations, deviating from the long-term goal of leading green development. In order to meet the requirements of long-term development, it is necessary to establish an incentive mechanism to support technological innovation of enterprises, promote enterprises to carry out technological innovation spontaneously, and play the main role to assume social responsibilities.

In addition, it is necessary to establish a policy effect evaluation system to effectively promote the exploration and practice of green bonds. A reasonable evaluation of the effect of the green bond policy will help to understand the effectiveness of the implementation of the policy and the obstacles faced in the process of advancing it. The current research on the effects of green bond policies is obviously lagging behind the practical development of green bond policies. A green bond policy effect evaluation system should be established, an environmental risk evaluation system should be formulated, and green bond evaluation standards should be unified to incorporate the green bond policy effect evaluation system into the green bond policy design and actual implementation process. Overall, these results offer a guideline for promoting the development of green bonds for the better and transforming the economy to environmental protection.

\section{References}

[1] Wei Wei, Xiao Qinglan, Chen Renjun. Export trade, technology effect and enterprise pollution emissions: Evidence from China's industrial enterprises [J]. Journal of Central China Normal University (Humanities and Social Sciences Edition), 201, 60 (05): 65 - 79.

[2] Wang Bo, Dong Zhennan. The improvement of green finance System in China: A Case study of green bond, green credit and green fund [J]. Finance and Economics, 2020 (04): 84 - 90.

[3] Hu, G., Wang, X. and Wang, Y., 2021. Can the green credit policy stimulate green innovation in heavily polluting enterprises? Evidence from a quasi-natural experiment in China.

[4] Zerbib, O., 2021. The effect of pro-environmental preferences on bond prices: Evidence from green bonds.

[5] Heine, D., Semmler, W., Mazzucato, M., Braga, J., Gevorkyan, A., Hayde, E. and Radpour, S., 2021. Financing Low-Carbon Transitions Through Carbon Pricing and Green Bonds.

[6] Sangiorgi, I. and Schopohl, L., 2021. Why do institutional investors buy green bonds: Evidence from a survey of European asset managers.

[7] Fatica, S., Panzica, R. and Rancan, M., 2021. The pricing of green bonds: Are financial institutions special?

[8] Tang, D. and Zhang, Y., 2021. Do shareholders benefit from green bonds. Proquest.com. 2021. POLL: growing green bonds - ProQuest.

[9] Cao C., Wang H.,1998. Research on the evaluation index system of enterprise technology innovation capability.

[10] Zhao X., 2003. Environmental Protection and the International Competitiveness of Industries: A Theoretical and Empirical Analysis.

[11] Cao T., Zhang C., Y., 2021. Green effects and impact mechanisms of green credit policies--Evidence based on green patent data of Chinese listed companies.

[12] Lu J., Yan Y., and Wang T., 2021.A study on the micro effects of green credit policy - based on the perspective of technological innovation and resource reallocation.

[13] Yang, T., 2015. POLL: growing green bonds - ProQuest. [online] Proquest.com.

[14] Yang X. 2013. Study on the Impact of Intellectual Property Innovation Capability on Enterprise Value of Small and Medium-sized Enterprises.

[15] Narin, F., Noma, E. and Perry, R., 2021. Patents as indicators of corporate technological strength.

[16] Luo X., Hu L., 2017. Study on the relationship between invention patents and financial performance of large enterprises.

[17] Tseng, F., Hsieh, C., Peng, Y. and Chu, Y., 2021. Using patent data to analyze trends and the technological strategies of the amorphous silicon thin-film solar cell industry.

[18] Mi J., Zhang S., Huang Bo.,2019. Patent ownership, market control and enterprise value enhancement--a study based on patent data of listed companies. 
Volume 16 (2021)

[19] Tuhkanen, H. and Vulturius, G., 2021. Are green bonds funding the transition? Investigating the link between companies' climate targets and green debt financing. [online] Taylor \& Francis.

[20] Laforet, S., 2021. Organizational innovation outcomes in SMEs: Effects of age, size, and sector. 